\title{
State-dependent retention in humans induced by alterations in affective state
}

\author{
MICHAEL L. MACHT, NORMAN E. SPEAR, and DONALD J. LEVIS \\ State University of New York, Binghamton, New York 13901
}

\begin{abstract}
Three experiments were conducted to determine whether an internal negative affective state might interact with human recall of verbal material. Threat of electrical shock accompanied both or neither presentation of words and a recall test, or one but not the other. The question was whether the internal context or affective state caused by the threat, during only learning or only recall, would induce state-dependent retention (poorer recall when the internal states accompanying learning and recall are different than when they are the same). The results indicated that a shift in affective state may induce state-dependent retention, but the conditions necessary for this effect remain unclear.
\end{abstract}

The phenomenon of state-dependent retention (SDR) refers to the empirical finding that retention of a previously learned event shows less of a decrement during testing when the testing situation reintroduces the "state" that accompanied the original training. The term "state" usually refers to a discriminable internal reaction within the organism present during training but orthogonal to it. "States" of the organism can be produced by drug ingestion, deprivation manipulations, affective reactions, or any other variables which result in a consistent internal response pattern.

The SDR effect has been studied most extensively with exogenous drugs as a means of inducing state changes for comparative purposes. For example, with infrahuman organisms, agents such as curare (Girden \& Culler, 1937), chloıpromazine (Otis, 1964), and pentobarbitol (Bliss, 1973) have been found successful in producing SDR. That is to say, better retention was obtained when the drug state was the same than when it differed between training and testing. In human subjects, SDR has been studied most frequently using alcohol as the "state" agent (e.g., Storm \& Caird, 1967), although other agents have been found to produce the effect (Eich, Weingartner, Stillman, \& Gillin, 1975).

The SDR phenomenon is not always easily reproducible and many of the studies in the area are plagued with methodological problems. The boundary conditions for producing the SDR effect are also not fully understood. For example, work with human subjects indicates the effect is more robust when free recall of words is tested, yet only initial steps toward analyzing this situation have been made (e.g., Weingartner, Adefris, Eich, \& Murphy, 1976). Further-

This research was supported in part by a grant from the National Science Foundation (BMS 74-24194). The authors wish to thank Steve Nettler and Elane Goldstein for their contributions throughout the course of this research. Requests for reprints should be addressed to Norman E. Spear, Department of Psychology, State University of New York at Binghamton, New York 13901. more, at a theoretical level, the SDR effect should occur under a variety of state conditions (Bower, 1972; Spear, 1973, 1976; Underwood, 1969, 1972), yet support for the phenomenon rests entirely with pharmacologically induced states. This latter point is of particular concern because, if the theoretical impact currently stimulated by the SDR effect is to remain viable, the generality of the finding must be established.

The present research was motivated, in part, by a desire to determine whether SDR could be produced in a state other than that induced by drugs. The affective state was selected because of potentially important theoretical and applied implications. For example, it is conceivable that human psychopathology may be resistant to change because of state-dependent retention that impedes release of memories containing emotional attributes. In support of this hypothesis, clinical evidence exists that considerable success in redintegrating early painful memories of patients can be obtained by using a therapeutic, reactivating imagery technique designed to elicit anxiety (Levis, in press; Stampfl \& Levis, 1967). Initially, the patients were unable to report such memories when interviewed in a nonanxious state. To test the implication of these observations for SDR, as well as to address points raised earlier, a series of studies was undertaken. In each, an attempt was made to induce a state of anxiety by periodically administering to subjects mild electric shock during learning and free recall of a list of words.

\section{EXPERIMENT 1}

Experiment 1 was an initial attempt to test SDR with the shock treatment. In this experiment, the standard 2 by 2 factorial design was employed. The subjects learned a list of nouns either in the presence or absence of mild electric shock and subsequently recalled these items under one of the two conditions.

\section{Method}

Design. The design of Experiment 1 was a 2 by 2 between- 
subjects factorial. The two factors represented the levels of the shock treatment during learning and testing; half of the subjects received shock (S) during presentation of words to be learned and the other half were presented the words in the absence of shock (NS). Each of these groups was then subdivided according to the treatment administered during testing; Groups S-S and NS-S recalled the words in the presence of shock or threat of shock, and Groups S-NS and NS-NS recalled in the absence of shock.

Subjects. The subjects were recruited from several undergraduate courses in psychology at the State University of New York at Binghamton. A total of 35 subjects took part in this experiment, each being paid $\$ 3$ for his/her participation. The subjects understood, however, that once the session began, they were free to terminate the experiment at any time without forfeit of payment. Upon arrival for the experimental session, each subject was randomly assigned to one of the four experimental groups, with the restriction that all four conditions be replicated before the next block began.

Apparatus. The experiment was carried out in a soundproofed room containing a finger-withdrawal apparatus consisting of a telegraph key and metal plate. When the subject pressed down on the key and plate simultaneously, a circuit was completed that allowed for the delivery of an electric shock. A panel containing three colored light bulbs was mounted above the apparatus. The subject's response was to withdraw his hand from the plate and key whenever a light bulb was turned on.

The experiment was controlled from an adjacent room. The programming of the lights and shock delivery was accomplished by Lafayette timers and a shock generator situated in this room. A two-way intercom allowed communication between the experimenter and the subject. The instructions and study items were recorded on tape and played back to the subject by a Wollensak tape recorder. The recordings were transmitted through headphones which the subject wore throughout the experiment.

Materials. A list of 25 nouns, all of medium frequency (1-39 per million) was selected from the Thorndike-Lorge norms.

Procedure. Prior to both the learning and recall phases, all subjects were given five finger-withdrawal trials. Each trial commenced with the onset of one of the three colored light bulbs mounted on the panel. The subject was required to withdraw his hand from the plate and key when a bulb was lighted. Following this response, the subject returned his or her hand to the apparatus and a new trial was begun. Subjects assigned to the shock conditions received an inescapable shock ( $2 \mathrm{~mA})$ on the second and fourth withdrawal trials.

During the learning phase, the 25 study words were presented over the headphones. All items were presented twice, one every $7 \mathrm{sec}$. Ten withdrawal trials were superimposed during list presentation (each trial occurred on the average of once every $30 \mathrm{sec}$ ). Shock was administered to the appropriate groups on the second and sixth trials. At the conclusion of this phase, a 15 -min retention interval was begun, during which the subjects were required to read a National Geographic magazine in order to minimize any further processing of the items.

The recall phase began with an initial set of five withdrawal trials. This was followed by a 5-min interval, during which the subject was required to recall (orally) as many of the list items as possible. During this interval, 10 withdrawal trials were superimposed (a lighted bulb occurring on the average of once every $30 \mathrm{sec}$ ) and shock was administered to subjects in the appropriate groups on the second and sixth trials. The experimenter recorded each item that the subject recalled.

All subjects were run individually. Upon arrival for the experimental session, each subject received instructions regarding the general nature of the experimental task. In order to maintain anxiety throughout the full duration of the learning and recall phases, subjects in conditions involving shock were led to believe they would receive a shock to any of the three light bulbs if they did not respond fast enough. Each subject repeated the instructions to insure understanding of the task. Following this, the experiment was begun.

\section{Results}

For each subject, the mean number of items recalled was computed. A 2 by 2 unweighted means analysis (Keppel, 1973) was performed on the data. The results indicated that the main effect of the shock treatment was not significant during either study or test. However, the critical statistic reflecting the SDR effect is the interaction term, and this was statistically significant $[F(1,31)=5.50, p<.05]$. This interaction indicated that subjects receiving the same treatment (shock or no shock) during the learning and recall phases recalled a significantly greater proportion of items (.55) than those subjects receiving different treatments in these two phases (.38). The mean proportion of items recalled in each of the four experimental groups is displayed in Figure 1. These results suggest that our shock treatment yielded SDR as a consequence of manipulations of affective state.

\section{EXPERIMENT 2}

Experiment 2 had several purposes. First, it appeared desirable to assess both the reliability and validity of the findings obtained in Experiment 1. Thus, one purpose of Experiment 2 was to replicate the initial findings. In addition, the affective states of the subjects in Experiment 2 were monitored in terms of their galvanic skin response (GSR) at selected intervals throughout the experimental session. The purpose of this procedure was to assess the relationship between the GSR measure and retention performance. It was expected that the GSR would provide empirical evidence that the shock treatment did in fact alter the level of

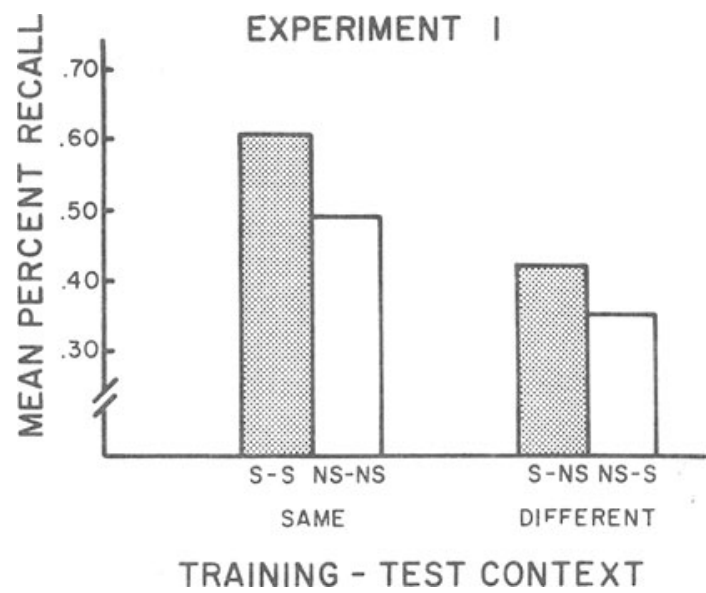

Figure 1. Mean percent recall in the same- and differentcontext groups in Experiment 1. 
anxiety aroused in the subjects, and that this was the critical factor mediating the SDR effect.

An additional purpose of Experiment 2 was to examine state-dependent effects on both recognition and recall to provide further evidence relevant to the question of recall vs. recognition differences (cf. Anderson \& Bower, 1972; Watkins \& Tulving, 1975).

\section{Method}

Design. Experiment 2 was a 2 by 2 by 2 between-subjects factorial. These factors reflected the treatment administered during study and test, respectively, and the order in which the retention tests were presented to the subject (recall first or recognition first). This design resulted in eight experimental groups. In Group S-SRgRc, recognition was tested first, while in Group S-SRcRg, recall was tested first. The same held for Groups S-NSRgRc and S-NSRcRg, NS-SRgRc and NS-SRcRg, and NS-NSRgRc and NS-NSRcRg.

Subjects. The subjects were 80 undergraduates attending the State University of New York at Binghamton who participated in this experiment in partial fulfillment of course requirements in introductory psychology. Upon arrival for the experimental session, each subject was randomly assigned to one of the between-subjects conditions, which were replicated in blocks of eight.

Apparatus. In addition to the apparatus described previously, a Stoelting galvanic skin response apparatus was used to monitor changes in skin conductance. These changes were recorded by a pen mounted on a moving roll of paper.

Materials. The study items were those used previously in Experiment 1. The recognition list consisted of the 25 study items (positives) and 25 distractors, each of which was related semantically to one of the study words.

Procedure. Several additional features were incorporated into the basic procedure of Experiment 1. As in Experiment 1, the subjects received five withdrawal trials prior to each of the learning and recall phases. In addition, the subject received five such trials prior to the recognition test. For recognition, the list of 50 items was presented orally via the tape recorder at a rate of one item every $7 \mathrm{sec}$. As each item was presented, the subject was required to respond (orally) either "yes" or "no," according to whether he thought the item had appeared in the study list. As with recall, 10 withdrawal trials were superimposed during recognition testing, and subjects in the appropriate groups were administered shock on 2 of these 10 trials. Subjects assigned to conditions given shock during the testing phase were administered this treatment during both the recognition and recall tests.

During selected intervals throughout the experimental session, each subject was monitored for GSR. The recording electrodes were applied to the subject's right hand prior to the start of the experimental session. Following this, the subject was encouraged to relax for a 5-min interval in which minimal stimulation occurred. During the last minute of this interval, the Stoelting apparatus was activated to permit recording of a baseline GSR measure. GSR readings were also taken at 1-min periods immediately following each of the learning, retention interval, and test phases. During each of these periods, each of the three lights was randomly presented twice. The purpose of this was to measure any anxiety-arousing properties which might have accrued to the lights as a result of the shock administration.

\section{Results}

To evaluate retention, the mean proportion of items recalled was computed for each subject. In addition, the mean proportion of hits and false alarms was calculated.

The results of Experiment 2 were essentially negative with respect to SDR. Neither the recognition nor the recall data provided any indication of SDR nor any main effect of shock treatment. The only significant effect to emerge from the analyses was an interaction between the order of testing and the learning treatment $[F(1,72)=6.20, p<.05]$. This interaction revealed that for the groups learning the items under the no-shock condition (NS-S and NS-NS), recall was higher when preceded by the recognition test $(.60)$ than when tested initially (.44).

Furthermore, no consistent relationship between the GSR measure and the experimental treatment emerged from the data. GSR scores for each subject in each group were derived by summing the number of deflections of the recording pen within each recording interval. The results indicated the shock treatment during either learning or testing had no systematic influence on the pattern of GSR scores obtained within each subject.

\section{EXPERIMENT 3}

To account for the negative results of Experiment 2, it was hypothesized that the modifications in procedure in Experiment 2 might have rendered the shock treatment relatively ineffective as a means of controlling the subject's affective state. Specifically, it seemed possible that the context in which the experimental session was conducted (i.e., the subject's contact with GSR electrodes) might have been sufficient to arouse an emotional reaction in the subjects which would override any effects produced by the shock treatment. Therefore, Experiment 3 was carried out as an exact replication of Experiment 1.

\section{Method}

In almost all respects, the method in Experiment 3 was identical to that in Experiment 1. The only exception concerned the subjects. In Experiment 3, 48 subjects attending the State University of New York at Binghamton participated in partial fulfillment of course requirements in introductory psychology and were not paid. Each subject was randomly assigned to one of the four treatment groups.

\section{Results}

For each subject, the mean proportion of items recalled was computed. Statistical analysis provided no evidence for SDR.

\section{FURTHER ANALYSIS OF THE DATA AND DISCUSSION, EXPERIMENTS 1-3}

While SDR was apparently obtained in Experiment 1, the basic statistical analy sis for Experiments 2 and 3 did not confirm the reliability of this effect. Furthermore, the results of Experiment 2 provided no evidence to suggest that the experimental treatment had any systematic effects on variations in the subjects' emotional state (as measured by GSR).

Perhaps the best explanation for these results is that the present procedures did not achieve adequate control over the subjects' affective state and that extraneous factors interacted with effects produced by the shock treatment to mask any SDR effects. For example, our technique might have been 
unsuccessful in maintaining a state of anxiety throughout the entire duration of list learning. Perhaps subjects adapted to the noxiousness of the shock over the course of list learning, or perhaps through occupation with learning activities (rehearsing, imaging, organizing, etc.) the subjects were not as anxious as they would have been had they been preoccupied solely with attending to the light panel. It therefore is possible that items from different portions of the same list were learned in effectively different contexts, and so use of overall recall scores as the dependent measure may have obscured any SDR effects.

This hypothesis predicts that SDR effects would be localized in items occurring in the early serial positions within the study list. To evaluate this hypothesis, individual serial position curves were obtained from the data for each subject. This analysis suggested that the results of Experiment 3 did indeed replicate those of Experiment 1 in that SDR effects were manifested in items from the early list positions in Experiment 3. A 2 by 2 analysis of variance performed on the proportion of items recalled from Serial Positions 1-5 confirmed this statistically $[F(1,44)=9.23, p<.05]$. The means corresponding to this effect are displayed in Figure 2.

Another factor concerns the sex of the subject or the interaction between experimenter sex and subject sex as a determinant of the subjects' emotional reactivity. Such effects are not unknown in other areas of research, especially with respect to manipulations concerned with emotional state, and perhaps these obscured the effects of the shock treatment found when both males and females were analyzed together. To evaluate this hypothesis, the data of all three experiments

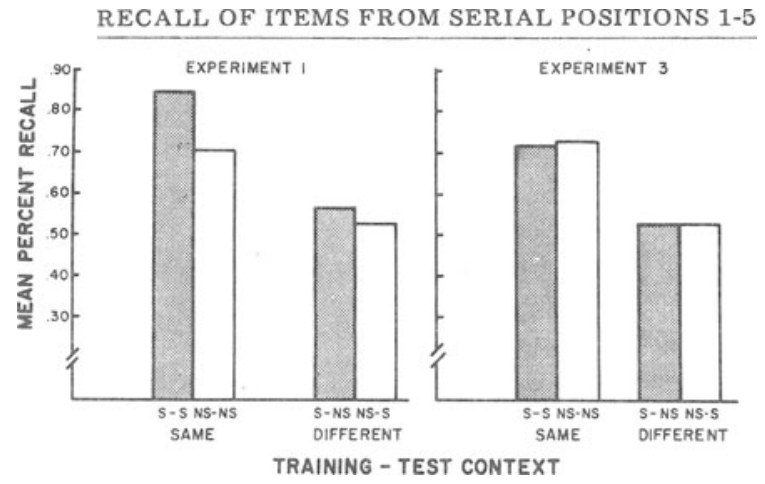

Figure 2. Mean percent recall of items from Serial Positions $1-5$ in the same- and different-context groups in Experiments 1 and 3.

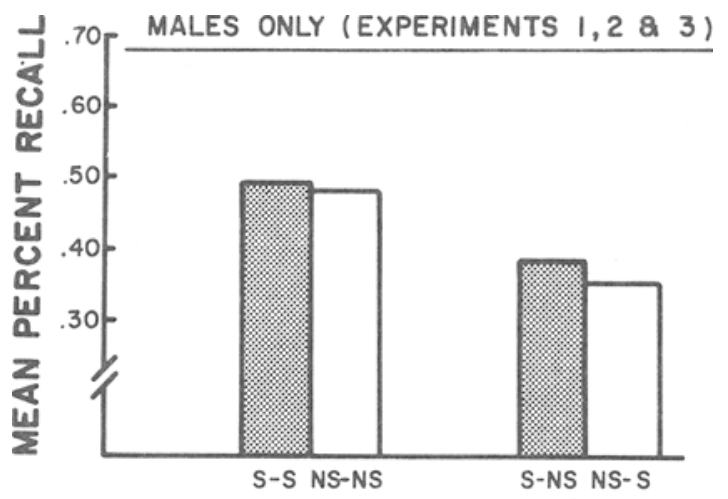

TRAINING - TEST CONTEXT

Figure 3. Mean percent recall of males only in the sameand different-context groups. These data are combined from all three experiments. (in Experiment 2, those groups tested initially for recall) were partitioned on the basis of the sex of the subjects. An analysis of variance indicated that across all three experiments, a significant SDR effect was indeed manifested, but for male subjects only $[F(1,48)=5.90, p<.05]$ (see Figure 3 ). Aside from these two factors, additional, albeit unknown, factors may have had similar masking influence on the outcomes of these experiments.

While the overall evidence is weak, these initial findings suggest that under the appropriate conditions, manipulations of a subject's psychological context such as "mood" or affective state, have the potential to produce SDR. This is to be expected given the theoretical emphasis placed upon the importance of internal contextual stimuli as determinants of memory retrieval (cf. Bower, 1972; Underwood, 1972). To date, few systematic studies of this kind have been conducted, and obviously, further research is needed to evaluate these notions.

\section{REFERENCES}

Anderson, J. R., \& Bower. G. H. Recognition and retrieval processes in tree recall. Psychological Review, 1972, 79. 97-123.

Bliss. D. K. Dissociated learning and state-dependent retention induced by pentobarbitol in the rhesus monkey. Journal of Comparative and Physiological Psychology. 1973, 84, 149-161.

BowER. G. H. Stimulus-sampling theory of encoding variability. In A. W. Melton \& E. Martin (Eds.). Coding processes in human memory: Washington. D.C: Winston. 1972.

Eich. J.. Weingartner. H., Stillman. R., \& Gillin, J. State-dependent accessibility of retrieval cues and retention of a categorized list. Journal of Verbal Learning and Verbal Behuvior. 1975. 14. 408-417.

Girden. E.. \& Culler. E. Conditioned responses in curarized striate muscle in dogs. Journal of Comparative Psychology. 1937. 23. 261-268.

KePPEL. G. Design and analisis: $A$ researcher's handbook. Englewood Cliffs. N.J: Prentice Hall. 1973.

LEVIS. D. J. Implementing the technique of implosive therapy. In D. Foa \& A. Goldstein (Eds.). Handbook of behavioral interventions. New York: Wiley, in press.

Otis. L. Dissociation and recovery of a response learned under the intluence of chlorpromazine or saline. Science, 1964. 143. $1347-1348$.

SpeAR. N. E. Retrieval of memory in animals. Psychological Revien, 1973. 80. 163-194.

SPEAR, N. E. Retrieval of memories: A psychobiological approach. In W. K. Estes (Ed.). Handbook of learning and cognitive processes: IV. Attention and memory. Hillsdale. N.J: Erlbaum. 1976.

Stampfl, T. G., \& Levis, D. J. Essentials of implosive therapy: A learning theory based on psychodynamic behavioral therapy. Journal of Abnormal Psychology, 1967, 72, 496-503.

STORM. T., \& CAIRD, W. K. The effects of alcohol on serial verbal learning in chronic alcoholics. Psychonomic Science, 1967, 9. 43-44.

Underwood. B. J. Attributes of memory. Psychological Review, $1969,76,559-573$.

UNDERWOOD. B. J. Are we overloaling memory? In A. W. Melton d E. Martin (Eds.). Coding processes in human memony. Washington. D.C: Winston, 1972.

Watkins. M. J.. \& Tulving. E. Episodic memory: When recognition fails. Journal of Experimental Psychology: General. 1975, 104, 5-29.

Weingartner, H., Adefris, W., Eich, J. E., \& Murphy, D. L. Encoding-imagery specificity in alcohol-state-dependent learning. Journal of Experimmental Psychology: Human Learning and Memon: 1976. 2. 83-87.

(Received for publication July 18. 1977.) 